\title{
Editorial
}

\section{Awareness about Antibiotic Uses}

\author{
Chowdhury DKP ${ }^{1}$, Rahman $\mathrm{MF}^{2}$
}

Antibiotics, miracle drugs of twentieth century, saved millions of people from bacterial infection and saving millions every day. But at the beginning of 21 st century we are facing problem with some common infectious diseases, those were curable with available antibiotics, now not responding to those ${ }^{1}$. Number of such resistant infections are increasing day by day. Antibiotics those were considered highly effective against all sorts of bacteria are becoming ineffective. World Health Organization recently published a list of 12 infectious agents which are resistant to most of the available antibiotics and new drugs are urgently required ${ }^{2}$. This list is not the final, it will be increased day by day if the present antibiotic uses trend persist.

Antibiotic resistance is now a burning question to the prescribers. There are numerous causes for this but the main cause is the indiscriminate use of antibiotics $^{3}$. Studies of hospital and domiciliary prescribing have shown that up to $35 \%$ of antimicrobial courses administered in the UK may be inappropriate ${ }^{4}$. Alexander Fleming, discoverer of first antibiotic cautioned the world about this in the very beginning of antibiotic uses. In his prophetic Nobel lecture in 1945 he mentioned "It is not difficult to make microbes resistant to penicillin in the laboratory by exposing them to concentration not sufficient to kill them" the lower concentration knowingly and unknowingly. Not only taking antibiotic at low dose or for a shorter period by the patient is the cause of exposing microbes to lower concentration now. World War II was a historical turning point not only for the basis of political power and war tactics, but also for drugs and medical advances. Between 1939 and 1945, new medical techniques were developed as a direct response to new weaponry. During the war, the drug helped to reduce the overall number of amputations and deaths. Penicillin was so effective that production increased from 400 million units in early 1943 to more than 650 billion units per month by the end of the war $^{6}$ in 1945. Since the first antibiotic Penicillin, was discovered more than 100 compounds have been found, but no new class has been found since 1987. The lack of new drugs coupled with over-prescribing has led to bacteria becoming increasingly resistant to modern medicines ${ }^{7}$.

Antibiotics today are not only used by the infected persons. About $50 \%$ of antibiotic use is in human medicine- the remainder being given to animals ${ }^{3}$. Antibiotics use in animal health and feed also making microbes resistant to drugs and endangering human health $^{8}$. In this aspect awareness about the antibiotic uses is required among the prescribers and the users. This issue of the journal has published an article on "Basic Knowledge of Army Troops and their relatives in Rangpur towards Antibiotics". This is a time worthy work and publication, which reflects the knowledge and attitude of our troops regarding antibiotic use. The findings are similar to other studies and not encouraging to prevent microbial resistance. We are taking many measures to prevent antimicrobial resistance but the main users i.e. the patients have very poor knowledge about this issue. It is now widely accepted that a comprehensive response to anti-microbial resistance (AMR) will involve not just new antibiotics or improved prescription guidelines, but that a 'whole of society engagement' will be necessary, as the Global Action Plan on AMR puts it ${ }^{9}$. This will for instance include the creation of greater public awareness of AMR and a change in behaviour for both prescribers and consumer. It has therefore been positive to see that research areas not traditionally concerned with AMR are increasingly becoming involved in the scientific and public discourse ${ }^{10}$.

1. Brig Gen Dipak Kumer Paul Chowdhury, MBBS, MPhil, MMEd, Professor \& Head, Dept of Pharmacology, AFMC, Dhaka 2. Major General Md Fashiur Rahman, ndc, MBBS, LLB, FCGP, MBA, MSS, Commandant, AFMC, Dhaka. 
We the prescribers have to take initiative to enrich the users with the knowledge of antibiotics to save our future generation from dyeing from common infection due to lack of effective antibiotics against them. Government also have to take measures to prevent availability of antimicrobials without prescription of registered doctors. Antibiotic stewardship programmes, including education, should be implemented at global level and target stakeholders in hospital and community settings and be combined with public awareness campaigns. Long-lasting investments in educational activities and innovative tools to support appropriate use of antibiotics and adequate long-term planning are urgently required ${ }^{1}$. We must go with Dr. Stuart B Levy, President of Alliance for Prudent Use of Antibiotics (APUA) "Our mission is clear: we must work together to preserve the power of antimicrobials and to return these miracle agents to their rightful position as effective treatment of disease" ${ }^{\text {,11 }}$.

\section{References}

1. Alanis AJ. Resistance to Antibiotics: Are We in the Postantibiotic Era? Arch Med Res 2005 Nov-Dec; 36(6):697-705.

2. Who.int.(2017). [online] Available at: http://www.who.int/ medicines/publications/WHO-PPL-Short_Summary_25FebET_NM_WHO.pdf [Accessed 27 Aug. 2017]
3. Barbosa TM, Levy SB. The impact of antibiotic use on resistance development and persistence. Drug Resist Updat 2000 Oct; 3(5):303-311.

4. Farrington M. Chemotherapy of infections. In: Bennett PN Brown MJ and Sharma P. editors. Clinical Pharmacology. 11th ed. Churchill Livingstone 2005:162-71.

5. Nobelprize.org.(2017). [online] Available at: https://www nobelprize.org/nobel_prizes/medicine/laureates/1945/fleming-I ecture.pdf [Accessed 27 Aug 2017].

6. Bradley J. How did the invention of Penicillin affect World War-II. Classroom. Leaf Group Ltd, 2001-2007.

7. Knapton S. Science Editor. The Telegraph. Science, 7 January 2016.

8. Wegener HC. Antibiotics in animal feed and their role in resistance development. Current Opinion in Microbiology 2003; 6:439-45.

9. World Health Organization (2015), Global Action Plan on Antimicrobial Resistance, Geneva.

10. Littmann J. What makes antimicrobial resistance an ethical problem? The APUA Newsletter 2016; 34:1.

11. Emerald.tufts.edu.(2017). [online] Available at: http:// emerald.tufts.edu/med/apua/ [Accessed 27 Aug 2017]. 